\title{
NORADRENALINE SENSITIVITY IN HYPERTENSION MEASURED WITH A RADIOACTIVE SODIUM TECHNIQUE
}

\author{
BY \\ R. MOULTON, A. G. SPENCER, AND D. A. WILlOUGHBY \\ From the Medical Unit, University College Hospital Medical School
}

Received July 8, 1957

There have been reports of an increased sensitivity to adrenaline or noradrenaline of the blood vessels of patients with hypertension (Greisman, 1952; Lee and Holze, 1951). In an attempt to test such abnormal sensitivity preliminary observatons were made with intradermal injections of noradrenaline in normal and hypertensive subjects. Intradermal noradrenaline $(0.1 \mu \mathrm{g}$. $)$ gave an area of blanching which slowly faded, and the duration of the blanching was considerably increased in the hypertensive patients. However, the end point was indefinite and it was difficult to express the result quantitatively. A technique was therefore developed in which the rate of disappearance of radioactive sodium from muscle was measured before and after local injections of noradrenaline. Noradrenaline was chosen rather than adrenaline because it is now generally agreed that noradrenaline is liberated at sympathetic nerve endings. The results obtained have been correlated with the blood pressure of the subjects.

\section{METHODS}

The rate of disappearance of radioactive sodium $\left({ }^{24} \mathrm{Na}\right)$ from muscle was measured using the technique first described by Kety $(1948,1949)$ and reviewed by McGirr (1952). The method was modified by leaving the needle used for injecting ${ }^{24} \mathrm{Na}$ in situ. After an initial ${ }^{24} \mathrm{Na}$ clearance had been determined noradrenaline or saline was injected through the needle, and a further set of readings was taken from which the ${ }^{24} \mathrm{Na}$ clearance was calculated.

The following standard procedure was adopted. Observations were made at the bedside on subjects who had been resting in bed for at least 30 minutes. Exposure was reduced to the minimum. $0.2 \mathrm{ml}$. of isotonic saline containing ${ }^{24} \mathrm{Na}$ with an activity of $2-5 \mu \mathrm{C}$. was injected from the front into the quadriceps muscle about the mid-point of the thigh. This was washed in with $0.1 \mathrm{ml}$. of saline and the needle was left in situ. A screened gamma ray Geiger-Muller counter was placed along the side of the thigh and wedged in position. The subject was asked not to move the limb. The counting rates were recorded at half-minute intervals during the observation period using a direct reading counting rate meter. After three minutes equilibration a set of 20 readings was taken. $0.2 \mathrm{ml}$. of noradrenaline solution in saline $(0.5 \mu \mathrm{g} / \mathrm{ml}$. noradrenaline bitartrate, plus $5 \mathrm{mg} . / \mathrm{ml}$. ascorbic acid and $5 \mathrm{mg} . / \mathrm{ml}$. sodium metabisulphite as preservatives) was then injected through the same needle. This amount of noradrenaline was chosen as preliminary observations showed that this was the minimum amount regularly to produce a slight decrease in the clearance of ${ }^{24} \mathrm{Na}$ from the muscle of normal subjects. In control experiments the noradrenaline was replaced by saline containing the preservatives. After another three minutes equilibration a further set of readings was taken. Since the same size needle (Serum V) was used on each occasion the dead space was the same. The noradrenaline and control saline solutions were made up in ampoules and sterilized by steaming for 15 minutes. The noradrenaline content was checked weekly on the cat's blood pressure preparation. The needle prick caused only trivial discomfort. As the duration of the experiment was short, corrections for the decay of ${ }^{24} \mathrm{Na}$ and for the rising background due to recirculation of ${ }^{24} \mathrm{Na}$ were negligible and have not been made. When the counts were plotted against time the points fell, as expected, about an exponential curve, and by plotting log counts against time the points fell about a straight line. The equation of the line was calculated by the method of least squares and the slope obtained. From this the time taken for the counts to fall to half value $\left(\mathrm{T} \frac{1}{2}\right)$ was calculated, being $\log \frac{1}{2}$ times the reciprocal of the slope of the line. 
The time to half value after noradrenaline was calculated in the same way and the difference between the two values attributed to the effect of noradrenaline.

A diastolic blood pressure of $90 \mathrm{~mm}$. of mercury or more was taken arbitrarily to indicate hypertension. The age and sex distributions of subjects in the groups with normal and raised blood pressures were comparable.

\section{RESULTS}

The results of a typical observation are shown in Fig. 1. Fig. 2 is a diagram showing the kind of result obtained in subjects with normal and with raised pressures, and also the effect of replacing noradrenaline by the control saline solution. Noradrenaline decreased the rate of disappearance of ${ }^{24} \mathrm{Na}$ in all subjects and hence prolonged the time to half value. The results obtained from 13 observations on 10 subjects with normal pressure and from 28 in 20 hypertensive patients are summarized in the Table.

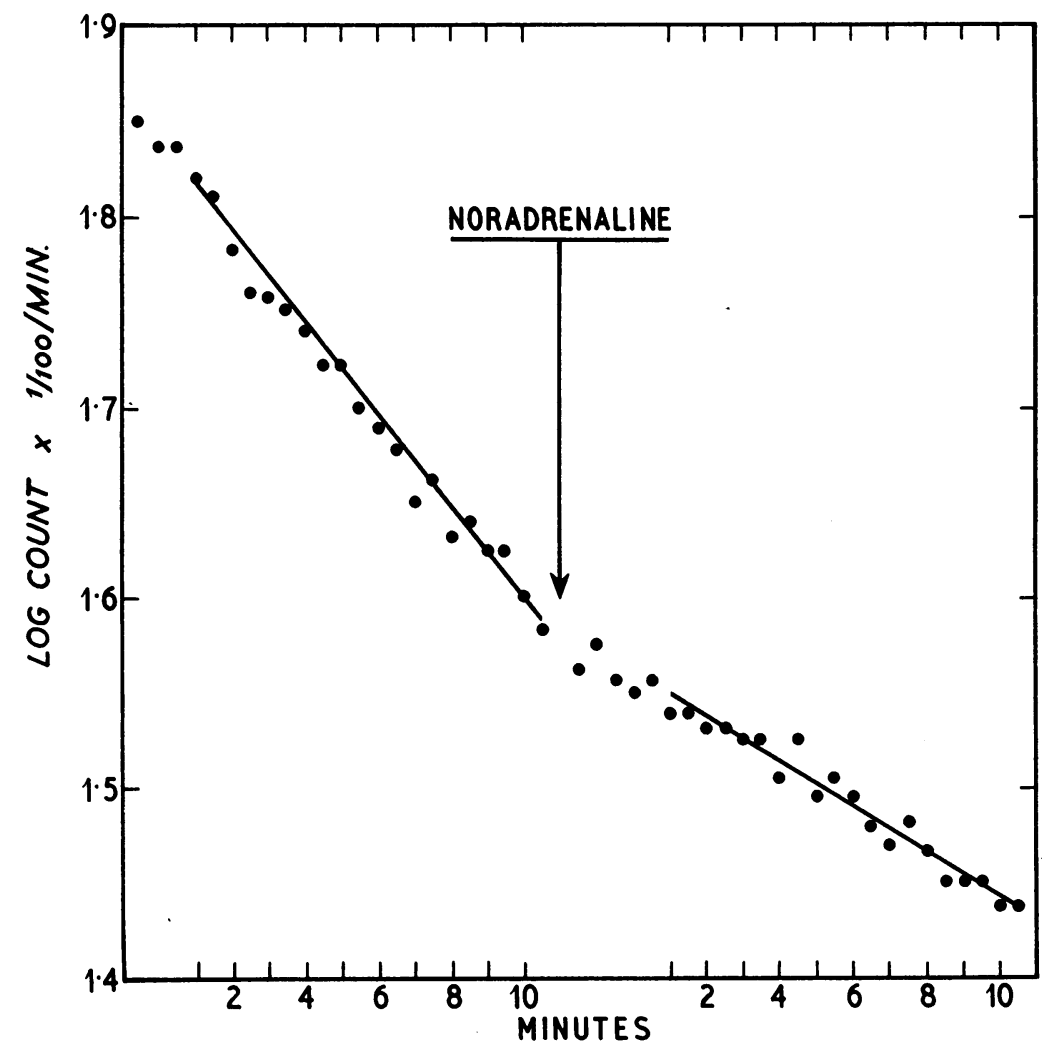

FIG. 1.-The effect of $0.05 \mu \mathrm{g}$ of noradrenaline on the clearance of $24 \mathrm{Na}$ from human quadriceps muscle.

The mean clearance rates of ${ }^{24} \mathrm{Na}$ in these groups did not differ significantly before noradrenaline, nor was there any difference in the mean clearances of the groups with normal and with raised pressures after noradrenaline. However, the mean change in time to half value after the injection of noradrenaline was significantly greater $(p \leqslant 0.001)$ in the hypertensive subjects, the mean increase being $13.9 \mathrm{~min}$. and for the normals $6.3 \mathrm{~min}$. This was true of both the absolute change in times to half value after noradrenaline and also of the change expressed as percentages of either initial or final times to half value. Thus the hypertensive subjects showed a greater change following noradrenaline than did the subjects with normal blood pressure.

The agreement between results of repeat observations on the same patient was poor, and was 
TABLE

Summary of the Results and the Statistical Tests applied to the Data

\begin{tabular}{|c|c|c|c|c|c|c|c|}
\hline & & & I & II & II-I & $\frac{\mathrm{II}-\mathrm{I}}{\mathrm{I}} \times 100$ & $\frac{\mathrm{II}-\mathrm{I}}{\mathrm{II}} \times 100$ \\
\hline & \multicolumn{2}{|c|}{$\begin{array}{c}\text { Blood pressure } \\
(\mathrm{mm} . \mathrm{Hg})\end{array}$} & \multirow{2}{*}{$\begin{array}{c}\text { Initial } \\
\text { time to } \\
\text { half value } \\
\text { (min.) }\end{array}$} & \multirow{2}{*}{$\begin{array}{c}\text { Time to } \\
\text { half value } \\
\text { after nor- } \\
\text { adrenaline } \\
\text { (min.) }\end{array}$} & \multirow{2}{*}{$\begin{array}{l}\text { Change in } \\
\text { time to } \\
\text { half value } \\
\text { (min.) }\end{array}$} & \multirow{2}{*}{$\begin{array}{l}\text { Percentage } \\
\text { change in } \\
\text { time to } \\
\text { half value }\end{array}$} & \multirow{2}{*}{$\begin{array}{l}\text { Percentage } \\
\text { change in } \\
\text { time to } \\
\text { half value }\end{array}$} \\
\hline & Systolic & Diastolic & & & & & \\
\hline $\begin{array}{l}\text { Mean of } 13 \text { observations on } 10 \\
\text { subjects with normal pressure .. } \\
\text { Standard deviation } \\
\text { Mean of } 28 \text { observations on } 20\end{array}$ & $\begin{array}{r}129 \cdot 6 \\
14.7\end{array}$ & $\begin{array}{l}68 \cdot 5 \\
13 \cdot 0\end{array}$ & $\begin{array}{r}21 \cdot 8 \\
9 \cdot 8\end{array}$ & $\begin{array}{l}28 \cdot 15 \\
11 \cdot 0\end{array}$ & $\begin{array}{l}6 \cdot 3 \\
5 \cdot 0\end{array}$ & $\begin{array}{l}32 \cdot 4 \\
30 \cdot 3\end{array}$ & $\begin{array}{l}21 \cdot 5 \\
14 \cdot 5\end{array}$ \\
\hline $\begin{array}{cc}\underset{\text { hypertensive subjects }}{\text { Standard deviation }} & \ldots\end{array}$ & $\begin{array}{r}183 \cdot 4 \\
29 \cdot 3\end{array}$ & $\begin{array}{r}118.6 \\
17.0\end{array}$ & $\begin{array}{r}18 \cdot 4 \\
5.8\end{array}$ & $\begin{array}{l}32 \cdot 3 \\
12 \cdot 0\end{array}$ & $\begin{array}{r}13 \cdot 9 \\
8 \cdot 7\end{array}$ & $\begin{array}{l}78 \cdot 1 \\
41 \cdot 7\end{array}$ & $\begin{array}{l}41 \cdot 2 \\
12 \cdot 7\end{array}$ \\
\hline 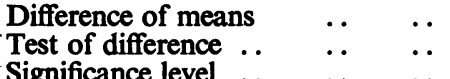 & & & $\begin{array}{r}3 \cdot 4 \\
1.2 \\
N S\end{array}$ & $\begin{array}{l}4 \cdot 15 \\
1 \cdot 2\end{array}$ & $\begin{array}{l}7 \cdot 6 \\
4 \cdot 3\end{array}$ & $\begin{array}{c}45 \cdot 7 \\
4 \cdot 6\end{array}$ & $\begin{array}{c}19 \cdot 7 \\
4 \cdot 6\end{array}$ \\
\hline $\begin{array}{l}\text { Correlation coefficient with di- } \\
\text { astolic blood pressure }\end{array}$ & & & $\begin{array}{l}\text { N.S. } \\
-0.17\end{array}$ & $\begin{array}{r}\text { N.S. } \\
+0.21\end{array}$ & $\begin{array}{r}0.001 \\
+0.44\end{array}$ & $\begin{array}{r}0.001 \\
+0.39\end{array}$ & $\begin{array}{r}0.001 \\
+0.63\end{array}$ \\
\hline $\begin{array}{l}\text { Significance level } \\
\text { Correlation coefficient with systolic }\end{array}$ & & & N.S. & N.S. & 0.01 & 0.01 & 0.001 \\
\hline $\begin{array}{rrrr}\text { blood pressure } & . & . & \ldots \\
\text { Significance level } & . & . & \ldots\end{array}$ & & & $\begin{array}{l}-0.19 \\
\text { N.S. }\end{array}$ & $\begin{array}{l}+0.11 \\
\text { N.S. }\end{array}$ & $\begin{array}{r}+0.32 \\
0.05\end{array}$ & $\begin{array}{r}+0.50 \\
0.001\end{array}$ & $\begin{array}{r}+0.51 \\
0.001\end{array}$ \\
\hline
\end{tabular}

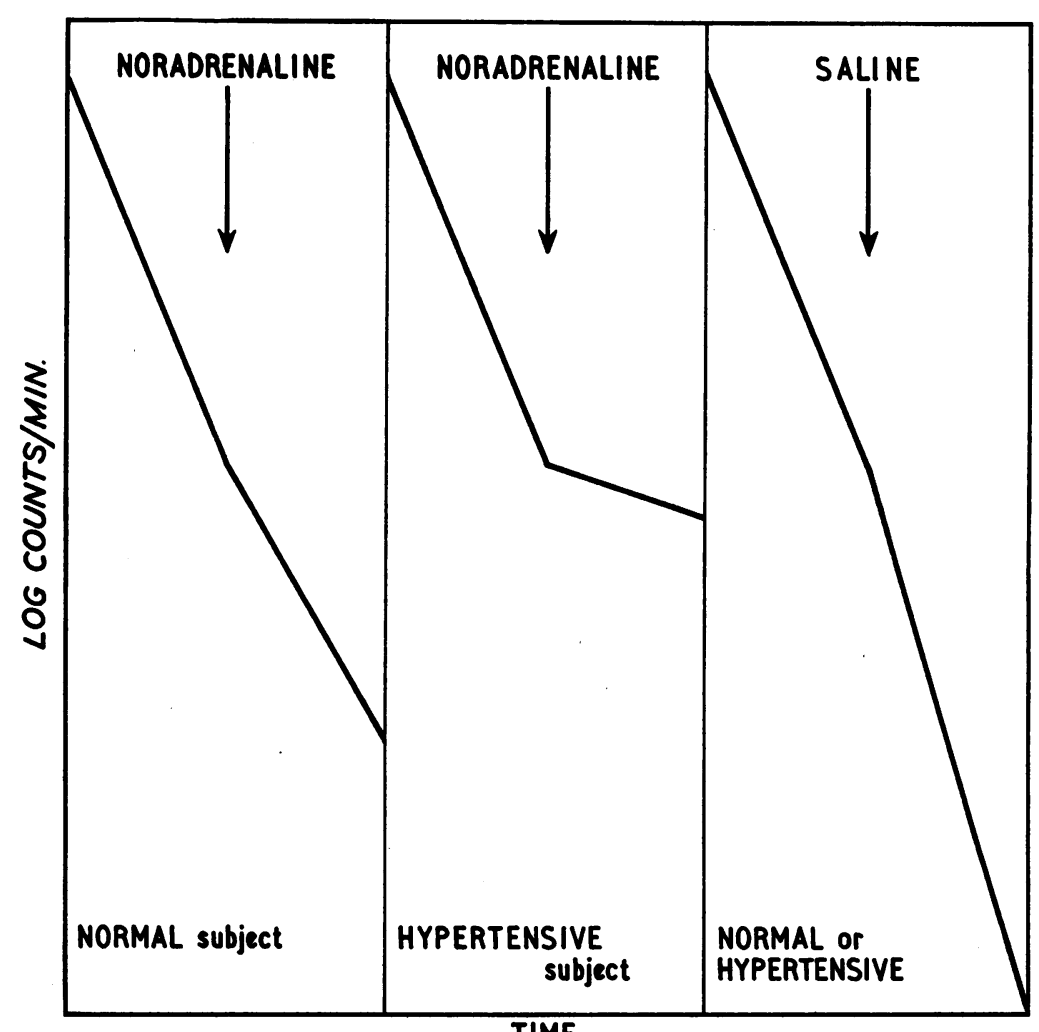

TIME

FIG. 2.-Diagram showing effect of noradrenaline and control saline on the clearance of ${ }^{24 \mathrm{Na}}$ from the muscle of subjects with normal pressure and with hypertension. 
worse when they were done on different days. Although our subjects have arbitrarily been divided into those with normal and those with a raised blood pressure, the level of the pressure is a continuous variable (Hamilton et al., 1954). Fig. 3 shows the difference between the times to half value (expressed as a percentage) before and after noradrenaline or saline, plotted against diastolic blood pressure. When the absolute change in time to half value is used as the ordinate or the systolic blood pressure as the abscissa similar graphs are obtained. These graphs all show a high degree of positive correlation between response to noradrenaline and the level of the blood pressure. The comparison of means and the correlation coefficients are given in the Table. Repeat observations on the same subject have been included, but the significance is not altered by taking only the first result. The significance was tested using the tables of Fisher and Yates (1953).

When noradrenaline was replaced by control injections of saline there was an increased clearance of ${ }^{24} \mathrm{Na}$ in 8 out of 9 observations (Fig. 3). The mean decrease in time to half value after injection. of saline was $4.4 \mathrm{~min}$. (S.D. $4.7 \mathrm{~min}$.).

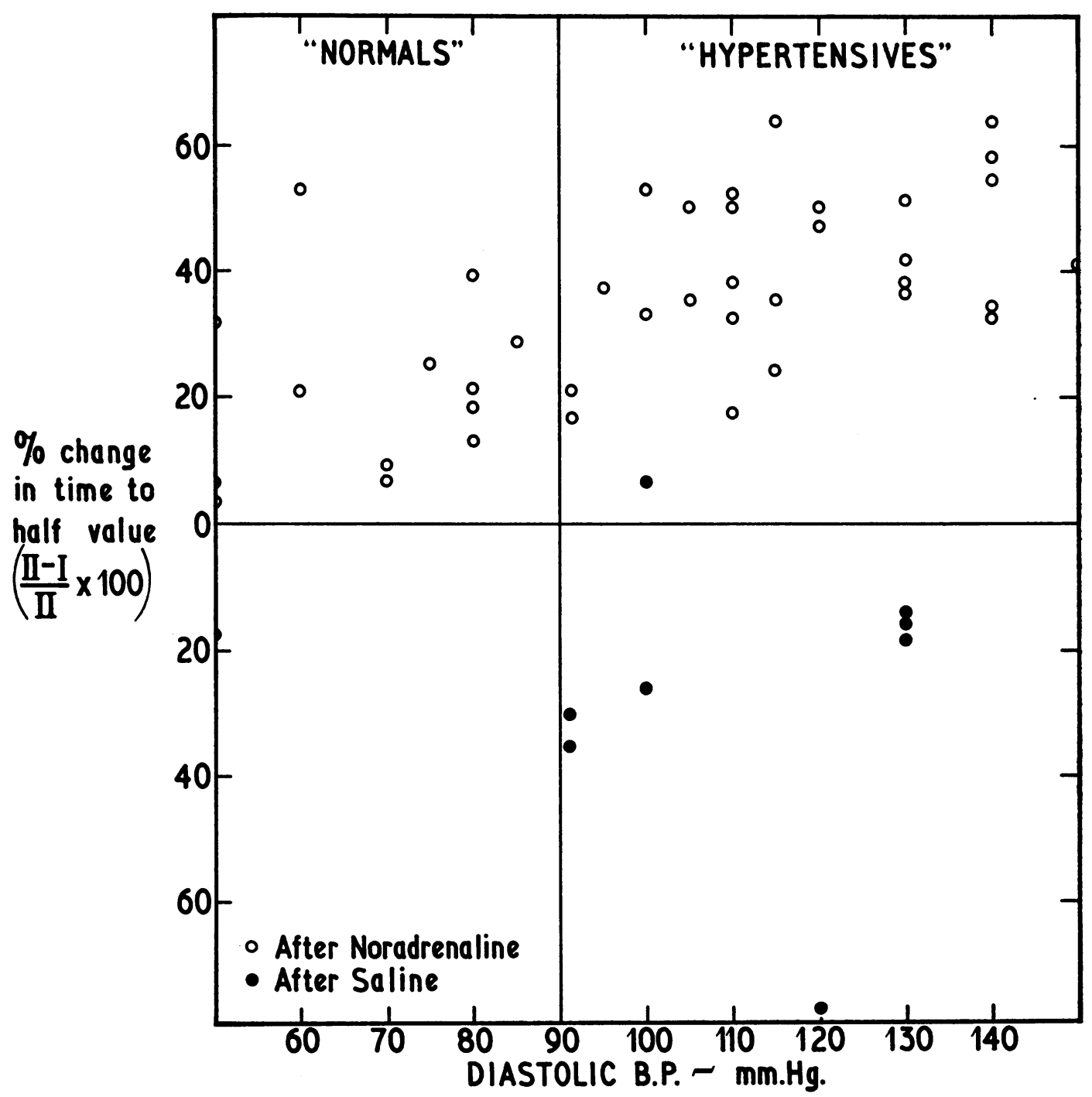

Fig. 3.-The percentage change in time to half value after noradrenaline or saline, and the diastolic blood pressure. 
The response to noradrenaline in renal or essential hypertension was found to be related only to the level of blood pressure and not to the cause of the hypertension.

\section{Discussion}

In these observations the ${ }^{24} \mathrm{Na}$ clearance has been used to measure the response to injected noradrenaline. The ${ }^{24} \mathrm{Na}$ clearance rates are probably the resultant of many different factors but we are concerned only with the change following local noradrenaline injections. Walder (1955) has shown that, within wide limits, a change in ${ }^{24} \mathrm{Na}$ clearance closely parallels a change in muscle blood flow. In this study, as expected, there was no correlation between the initial ${ }^{24} \mathrm{Na}$ clearance and the blood pressure. Even in severe peripheral vascular disease resting ${ }^{24} \mathrm{Na}$ clearances may not be altered (Cooper et al., 1949). The variation between different determinations in the same patient is in agreement with the results of others (Wisham et al., 1951; Reese et al., 1951; McGirr, 1952). Although the method does not give very reproducible results in the individual patient, statistically an increased sensitivity to noradrenaline has been found in the present group of hypertensive subjects.

The effect of intravenous infusions of noradrenaline on the blood pressure was investigated by Goldenberg et al. (1948), who found that hypertensive subjects gave a larger response than controls to the same dose. Judson et al. (1950) were not able to confirm this and considered that the percentage rise in the earlier workers' results did not differ from that of controls. Greisman (1952) has shown that the capillaries in the nail-bed are abnormally sensitive to noradrenaline in hypertension, and Lee and Holze (1951) using adrenaline, obtained comparable results by examining the conjunctival vessels. Using a plethysmographic technique, Duff $(1956,1957)$ has recently shown an increased response to intra-arterial injections of adrenaline in most hypertensive subjects, this effect being greatest in those most severely affected. The effect of noradrenaline was very much less than that of adrenaline.

These results, obtained by several workers using a variety of techniques and working on different vascular beds, seem to indicate an increased response of the peripheral vessels in hypertension to local pressor amines. This could result either from an increased sensitivity of the smooth muscle in the vessel wall, or from an impairment of the local mechanism which normally destroys or removes pressor amines.

\section{SUMMARY}

An increased sensitivity to intramuscular noradrenaline in hypertensive patients has been demonstrated using a ${ }^{24} \mathrm{Na}$ clearance technique.

We are grateful to Professor M. L. Rosenheim for encouragement and advice, to Mr. S. B. Osborne and Dr. H. S. Payling Wright for helpful discussions, to Mr. N. W. Please for help with the statistics, and to Mr. V. K. Asta for the Figures.

\section{REFERENCES}

Cooper, F. W., Jr., Elkin, D. C., Shea, P. C., Jr., and Dennis, E. W. (1949). Surg. Gynec. Obstet., 88, 711.

Duff, R. (1956). Hypotensive Drugs. Ed. M. Harington, Pergamon Press, London. (1957). Brit. Heart J., 19, 45.

Fisher, R. A., and Yates, F. (1953). Statistical Tables for Biological, Agricultural and Medical Research. Oliver and Boyd Ltd., Edinburgh.

Goldenberg, M., Pines, K. L., Baldwin, E. F., Greene, D. G., and Roh, C. E. (1948). Amer. J. Med., $5,792$.

Greisman, S. E. (1952). J. clin. Invest., 31, 782.

Hamilton, M., Pickering, G. W., Fraser Roberts, J. A., and Sowry, G. S. C. (1954). Clin. Sci., 13, 11.

Judson, W. E., Epstein, F. H., and Wilkins, R. W. (1950). J. clin. Invest., 29, 1414.

Kety, S. S. (1948). Amer. J. med. Sci., 215, 352.

(1949). Amer. Heart J., 38, 321.

Lee, R. E., and Holze, E. A. (1951). J. clin. Invest., 30, 539.

McGirr, E. M. (1952). Brit. med. Bull., 8, 192.

(1952). Clin. Sci., 11, 91.

Reese, H. L., Darrow, R. P., and Cullen, M. L. (1951). Surg. Gynec. Obstet., 92, 751.

Walder, D. N. (1955). Clin. Sci., 14, 303.

Wisham, L. H., Yalow, R. S., and Freund, A. J. (1951). Amer. Heart J., 41, 810. 